\title{
Current Characteristics Analysis and Fault Injection of an Early Weak Fault in Broken Rotor Bar of Traction Motor
}

\author{
Jintian Yin,,2 Yongfang Xie,' Tao Peng $\mathbb{D}^{1},{ }^{1}$ Chunhua Yang, ${ }^{1}$ and Zhiwen Chen ${ }^{1}$ \\ ${ }^{1}$ School of Information Science and Engineering, Central South University, Changsha 410083, China \\ ${ }^{2}$ Hunan Provincial Key Laboratory of Grids Operation and Control on Multi-Power Sources Area, Shaoyang University, \\ Shaoyang 422000, China \\ Correspondence should be addressed to Tao Peng; pendtao@163.com
}

Received 12 July 2018; Accepted 23 September 2018; Published 10 October 2018

Academic Editor: Yang Tang

Copyright (C) 2018 Jintian Yin et al. This is an open access article distributed under the Creative Commons Attribution License, which permits unrestricted use, distribution, and reproduction in any medium, provided the original work is properly cited.

\begin{abstract}
Aiming at the destructive and irreversible problems of the broken rotor bar fault of the traction motor, the current characteristics of the early weak fault of the single bar are analyzed, and the broken rotor bar fault simulation injection is realized on the experimental platform. Firstly, a damage factor from the change rule of the metal resistance value of a rotor bar is defined. By means of such a damage factor, the relationship between the severity of the fracture of a single rotor bar and the phase resistance of the traction motor was obtained. Through the superposition principle, the traction motor in the fault of the rotor bar was regarded as a normal motor in which the reverse current source was superimposed on the fault rotor bar. The characteristic values of the stator current fault component were obtained when the single bar had broken. Finally, the relationship between the fault characteristics component of the stator current and the fracture severity of the single rotor bar was established. On this basis, on hardware-in-the-loop fault injection benchmark of the traction drive control system based on dSPACE, the gradual injection of early weak faults in the early broken rotor bar was carried out and the results were analyzed. The experimental data demonstrated the correctness of the current characteristics analysis and fault injection.
\end{abstract}

\section{Introduction}

Traction motors are core equipment that convert electrical energy into mechanical kinetic energy as the power source for high-speed trains. Traction motors are also prone to faults and endanger the safety of passengers. According to the statistics [1-3], broken rotor bar is a common fault in traction motors. In the initial stage of this type of fault, it is weak and difficult to detect and has a little influence on the operation of motor. However, if maintenance or replacement is not performed at this time, the degree of fault further increases and the safety of the train becomes increasingly compromised. In addition, a broken rotor bar fault is easily to cause sweeping faults, resulting in serious faults such as grounding of the stator windings or short circuits, thus causing unexpected shutdowns and other accidents. Therefore, it is of great significance to study the fault monitoring of the early broken rotor bar of traction motor to prevent the occurrence of malignant accidents.
In the previous study [4], a new method for the diagnosis of broken rotor bar fault in induction motors based on sliding window discrete Fourier transform was proposed. The effect of sideband frequencies of the fundamental component amplitude of stator current was investigated. Other authors [5] used a start-up transient process and a multilabel classification framework to detect the broken rotor bar fault and mixed eccentricity faults. Furthermore, a study [6] used a nonuniform time resampling algorithm to realize fault diagnosis of the broken rotor bar under the soft start of the inverter power supply. Investigators [7] have also fulfilled the fault diagnosis of the broken rotor bar of medium voltage induction motor using an online MCSA (Motor Current Signature Analysis) method. Studies [8] observed that when the motor squirrel-cage rotor is asymmetrical, the side frequency component of $(1 \pm 2 k s) f_{1}(k=1,2,3 \ldots)$ will be generated in the stator current.

In another study [9], a fault diagnosis method for a broken rotor bar of squirrel-cage motor was presented 
when the load continuously changes, based on the extracted frequency spectrum of fault characteristics, to determine whether broken rotor bar fault occurred. A further study [10] observed that when a broken rotor bar fault occurs, the pulsating torque of synchronous speed will be introduced in the electromagnetic torque, and so the harmonic component will be introduced into the torque. Studies [11, 12] derived the relationship between phase resistance change of the rotor and the number of broken rotor bars in the induction motor through theoretical derivation.

The above-mentioned studies have made significant achievements in the study of broken rotor bar fault in squirrel-cage induction motors. However, these studies focused on multiple rotor bar fault. At present, few work have reported the early weak faults of a single broken rotor bar. Considering that the broken rotor bar fault of the traction motor is a destructive fault, the occurrence of the fault is random, there are many uncontrollable factors, and the broken rotor bar fault is an irreversible process, and the fault cost is high due to the man-made destruction of the motor. At present, the simulation of traction motors for highspeed trains is mostly based on normal operation, lacking in-depth research and simulation of faults. The software simulation is used to simulate the fault of the traction motor by using the fault injection method, which makes the research more flexible and cost-effective. Therefore, the relationship between rotor phase resistance and the fracture severity of a single rotor bar was studied. The stator current fault characteristics were analyzed when a single rotor bar was broken. The relationship between the fault characteristics component of the stator current and the fracture severity of rotor bar was established. On the hardware-in-the-loop fault injection benchmark of the traction drive control system with a certain type of high-speed train based on dSPACE, a gradient injection of the early weak fault of the broken rotor bar was realized. The injection results were analyzed to verify the correctness of the current characteristics analysis and fault injection.

The rest of the paper is organized as follows: Section 2 demonstrates an analysis of the early weak fault of a broken rotor bar. It includes rotor phase resistance and stator current analysis, as well as stator current with different fault severity. Section 3 presents the fault injection experiments and results including the hardware-in-the-loop fault injection benchmark, fault injection module, and experimental results and analysis. Section 4 gives the concluding remarks.

\section{Analysis of the Early Weak Fault of the Broken Rotor Bar}

2.1. Rotor Resistance Analysis. The total number of traction motor rotor bars was set to $N$, the resistance of each bar was set to $R_{B}$, and the resistance of the two end ring corresponding to rotor bar is $R_{E}$. The end ring resistance into the bar was converted, then the bar resistance is $R_{0}=$ $R_{B}+2 R_{E}$, because $R_{B} \gg R_{E}$, so $R_{0} \approx R_{B}$.

Figure 1 shows the equivalent diagram of the three-phase rotor winding of the traction motor. The number of winding

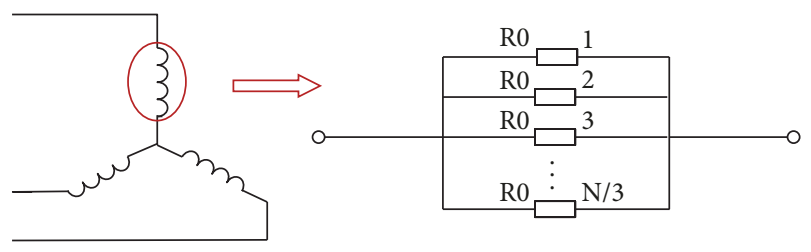

FIGURE 1: Traction motor rotor winding and equivalent circuit.

bars per phase is $N / 3$ and the phase bars are connected in parallel; when the bars are normal, the rotor resistance is

$$
R_{r}=\frac{R_{0}}{N / 3}=\frac{3 R_{0}}{N}
$$

When the early weak fault of a single rotor bar of traction motor occurs, the damage factor $\mathrm{D}$ is the percentage of the bearing area lost due to the presence of microdefects in the bearing surface of the rotor bar material, and $0 \leq \mathrm{D} \leq 1$; when $\mathrm{D}=0$, this indicates the guide bar is intact; when $\mathrm{D}=1$, the rotor bar is completely broken. Assuming that the normal rotor bar has a nondestructive bearing area $\mathrm{A}_{0}$, the damaged bearing bar has an effective bearing area $\mathrm{A}=\mathrm{A}_{0}(1-\mathrm{D})$, and the corresponding resistance values of $R_{0}$ and $R_{0}^{\prime}$ before and after damage of the single rotor bar are

$$
\begin{aligned}
& R_{0}=\rho \frac{L}{\mathrm{~A}_{0}} \\
& R_{0}^{\prime}=\rho \frac{L}{\mathrm{~A}_{0}(1-\mathrm{D})}
\end{aligned}
$$

where $\rho$ is the resistivity of the bar and $L$ is the length of the bar.

From (2) and (3), we have

$$
R_{0}^{\prime}=\frac{R_{0}}{(1-\mathrm{D})}
$$

At this time, one of the resistance values of the parallel circuit in Figure 1 will change from $R_{0}$ to $R_{0}^{\prime}$, and the corresponding phase resistance value will change from $R_{r}$ to $R_{r}^{\prime}$ :

$$
R_{r}^{\prime}=\frac{R_{0}}{N / 3-1} \| R_{0}^{\prime}=\frac{3 R_{0}}{N-3 D}
$$

The difference $\Delta R_{r}$ between the normal phase resistance and the weak resistance of a single rotor bar is

$$
\Delta R_{r}=R_{r}^{\prime}-R_{r}=9 R_{0} \frac{D}{N(N-3 D)}
$$

Based on (1), $R_{0}=N R_{r} / 3$. By substituting into (6), the phase resistances before and after the fault are changed:

$$
\Delta R_{r}=\frac{3 D}{N-3 D} R_{r}
$$

When $D=0, \Delta R_{r}=0$; when $D=1, \Delta R_{r}=(3 /(N-3)) R_{r}$. 
The damage factor can be obtained from the fatigue damage model developed in [13]:

$$
D=1-\left(1-\frac{N_{c}}{N_{f}}\right)^{1 /(n(\mathrm{r})+1)}
$$

where $N_{c}$ is the cycles number corresponding to the service life; $N_{f}$ represents the cycle number corresponding to the total life, which can be obtained through the repeated bending test of the material; $n(\mathrm{r})$ is the material constant, which can be obtained according to the check table of the rotor bar metal material.

2.2. Stator Current Analysis. Suppose the power supply frequency of the traction drive system to the traction motor is $f_{1}$, and the stator winding of the motor generates the base wave magneto-motive force $M_{1}$, which can be expressed as

$$
M_{1}=K_{1} N_{1} I_{1} \sin \left(\omega_{1} \mathrm{t}-\mathrm{P} \theta\right)
$$

where $K_{1}$ is a constant, which is related to the number of motor pole pairs and stator windings; $N_{1}$ is the series winding number of each phase of the stator winding; $I_{1}$ denotes the stator current; $P$ is the number of motor pole pairs; $\theta$ refers to the initial phase angle; $\omega_{1}$ is the stator current angular frequency.

The rotor winding phase angle is $\varphi=\theta-\omega_{r} t ; \varphi$ is the rotor phase angle; $\omega_{r}$ denotes the rotor rotation angular velocity; when the pole pair number is 1 , we obtain

$$
\left.M_{1}=K_{1} N_{1} I_{1} \sin \left[\left(\omega_{1}-\omega_{r}\right) \mathrm{t}-\varphi\right)\right]
$$

The rotor will generate the rotor magneto-motive force under the action of the rotating magnetic field of the stator, and the rotor magneto-motive force will be balanced with the stator magneto-motive force. The rotor fundamental magneto-motive force $M_{2}$ is expressed as

$$
M_{2}=K_{2} N_{2} I_{2} \sin \left[\left(\omega_{1}-\omega_{r}\right) \mathrm{t}-\varphi\right]
$$

where $K_{2}$ is a constant, which is related to the pole pair of the motor and the rotor winding; $N_{2}$ denotes the number of series windings of each phase of the rotor winding; $I_{2}$ is the rotor current.

The fault of the traction motor rotor bar can destroy the symmetry of the motor, while the rotor current magnetomotive force is modulated by $\sin 2 \varphi$, and $M_{2}$ becomes $M_{2 f}$, which can be expressed as

$$
\left.M_{2 f}=K_{2} N_{2} I_{2} \sin \left[\left(\omega_{1}-\omega_{r}\right) \mathrm{t}-\varphi\right)\right] \sin 2 \varphi
$$

By slipping $s=\left(\omega_{1}-\omega_{r}\right) / \omega_{1}$, we have $\omega_{r}=(1-s) \omega_{1}$. Because the stator magnetic potential and the rotor magnetic potential are balanced with each other, (12) can be rewritten as

$$
\begin{aligned}
M_{1} & =M_{2 f}=K_{2} N_{2} I_{2} \sin \left(\omega_{1} t-\theta\right) \\
& \cdot \sin \left[2(1-s) \omega_{1} t-2 \theta\right] \\
& =\frac{K_{2} N_{2} I_{2}}{2}\left\{\cos \left[(3-2 s) \omega_{1} t-3 \theta\right]\right. \\
& \left.-\cos \left[(1-2 s) \omega_{1} t-\theta\right]\right\}
\end{aligned}
$$

From (13) it can be seen that the component of the magneto-motive force contains a component of $(1-2 \mathrm{~s}) f_{1}$, which will be linked to the stator winding; thus the stator winding induces a potential voltage and current with frequency $(1-2 s) f_{1}$; the frequency reflects the characteristics of the broken rotor bar fault.

According to (4), the resistance of the rotor bar is $(1-D)$ times to fault. As the bar voltage of the motor is basically unchanged $(e=B L V)$, the current flowing through the bar when the rotor bar has an early weak fault is $(1-D)$ times to the normal current. The achieved currents are $i_{r 1}, i_{r 2}, i_{r 3} \ldots$, and $i_{r N}$, respectively, in the presence of normal motor rotor bar. By means of the superposition principle, the traction motor in the event of a rotor bar fault is regarded as the normal motor adding the reverse current source at the rotor bar with a fault. That is, the reverse current $i_{\text {add }}=-D i_{r 1}$ is superimposed on the original current $i_{r 1}$. When the rotor bar is completely broken $D=1$, the additional current is $i_{\text {add }}=-i_{r 1}$.

The current $i_{\text {add }}$ establishes the pulsed magneto-motive force, which is decomposed into two components, positive and negative rotations. All of the magnitudes are $0.9\left(\left(\left(\dot{I}_{\text {add }} / 2\right) \times 1 / 2\right) / P\right)[14]$. The positive rotating component induces a potential and current at the frequency $f_{1}$ in the stator winding. As this current value is relatively small compared to the fundamental current, it can be ignored. The $(1-2 s) f_{1}$ current component induced by the counterrotating component in the stator windings needs to be calculated. The reverse rotating magnetic field generated by superimposing the current $i_{\text {add }}$ on a single bar is equivalently expressed as a normal $N$ rotor bar flowing through the current $i_{r}$.

$$
0.9 \frac{\left(\dot{I}_{\text {add }} / 2\right) \times 1 / 2}{P}=0.9 \frac{N \dot{I}_{r} \times 1 / 2}{2 P}
$$

Equivalent current is $\dot{I}_{r}=\dot{I}_{a d d} / N=D \dot{I}_{r 1} / N$.

By converting this current to the stator side, we obtain

$$
\dot{I}_{r}^{\prime}=\frac{\dot{I}_{r}}{k_{i}}=\frac{D \dot{I}_{r 1}}{N k_{i}}
$$

$k_{i}$ is the current conversion factor, and the same motor $k_{i}$ value does not change.

Considering $\dot{I}_{r}^{\prime}$ as the current source, $\dot{I}_{(1-2 S)}$ can be obtained according to the equivalent circuit; the equivalent circuit is shown in Figure 2.

$$
\dot{I}_{(1-2 S)}=\dot{I}_{r}^{\prime} \frac{R_{m}+j X_{m}}{\left(R_{m}+j X_{m}\right)+\left(R_{1} /(1-2 s)+j X_{1}\right)}
$$

It can be seen from (15) that an early weak fault $\dot{I}_{r}^{\prime}$ is $D$ times when a single bar completely breaks. By combining with (16), it can be concluded that the amplitude of the side frequency current $\dot{I}_{(1-2 s)}$ in an early weak fault is $D$ times that of a single lead when it is completely broken.

Based on the above analysis, the stator current contains a fault characteristics current component with a frequency of $(1-2 s) f_{1}$. The fault component interacts with the air gap magnetic flux in the motor and causes the electromagnetic 


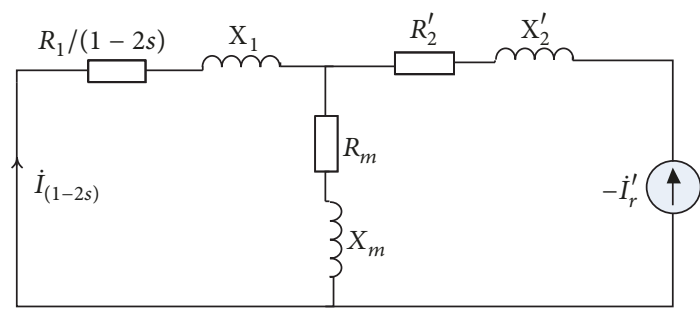

FIGURE 2: Calculated equivalent circuit of $\dot{I}_{(1-2 S)}$ component.

torque of the motor to fluctuate, leading to motor speed fluctuations. The fault component of $f_{b}=(1 \pm 2 k s) f_{1}$ is generated. Moreover, the amplitude of the side frequency current (fault characteristic component) is $D$ times when completely broken.

Considering the characteristics of components of the fault contained in the stator current when the traction motor breaks and the traction motor in the actual traction drive system has white noise with a very broad spectrum distribution and the stator current is expressed as

$$
\begin{aligned}
i_{s}= & A_{1} \cos \left[2 \pi f_{1} t+\theta_{1}\right] \\
& +A_{2} \cos \left[2 \pi(1-2 k s) f_{1} t+\theta_{2}\right] \\
& +A_{3} \cos \left[2 \pi(1+2 k s) f_{1} t+\theta_{3}\right]+\omega(t)
\end{aligned}
$$

$i_{s}$ is composed of four parts, the first part is the normal current signal $A_{1} \cos \left[2 \pi f_{1} t+\theta_{1}\right]$, the second and the third parts are the current signals of broken rotor bar fault characteristics $A_{2} \cos \left[2 \pi(1-2 k s) f_{1} t+\theta_{2}\right]$ and $A_{3} \cos \left[2 \pi(1+2 k s) f_{1} t\right.$, respectively, and the fourth part is the noise signal $\omega(t)$. In (17), $A_{1}$ represents the amplitude of basic frequency current signal; $A_{2}$ and $A_{3}$ are the amplitude of the current signals of fault characteristics, respectively, and their size reflects the severity of the fault. $k$ is the fault current order, $k=1,2,3, \cdots$, $\theta_{1}, \theta_{2}$, and $\theta_{3}$ are the fault current phase angle, and $\omega(t)$ is white noise.

2.3. Stator Current with Different Fault Severity. The magnitude ratio of the fault characteristic current to the fundamental current depends on the severity of damage to the traction motor rotor bar. The number of the broken rotor bars can be estimated by the following equation $[15,16]$ :

$$
n \approx \frac{2 N}{\left(I_{1} / I_{1 \pm 2 s}+2 P\right)}
$$

where $n$ is the number of broken rotor bars, $I_{1}$ and $I_{1 \pm 2 s}$ are the amplitudes corresponding to the fundamental frequency $f_{1}$ and the current frequency $(1 \pm 2 s) f_{1}$ of fault characteristics, respectively, and $P$ represents the number of motor pole pairs. When $n=1,2 N /\left(I_{1} / I_{1 \pm 2 s}+2 P\right) \approx 1$; that is,

$$
I_{1 \pm 2 s} \approx \frac{I_{1}}{2(N-P)}
$$

Equations (15) and (16) have shown that the amplitude of side frequency current in the early weak fault of the rotor bar is $D$ times that in the case of a single rotor bar broken completely. Therefore, when the rotor bar encounters early weak fault, we obtain

$$
I_{1 \pm 2 s} \approx \frac{D I_{1}}{2(N-P)}
$$

In (17), $A_{1}$ is the fundamental current amplitude, $A_{2}$ and $A_{3}$ are the current amplitudes of fault characteristics and $A_{2} \approx$ $A_{3}$, so $I_{1}, I_{1 \pm 2 s}$ can be replaced by $A_{1}, A_{2}\left(A_{3}\right)$ as

$$
A_{2} \approx A_{3} \approx \frac{1}{2} \frac{D}{N-P} A_{1}
$$

Therefore, (17) can be rewritten as

$$
\begin{aligned}
i_{s}= & A_{1} \cos \left[2 \pi f_{1} t+\theta_{1}\right] \\
& +\frac{1}{2} \frac{D}{N-P} A_{1} \cos \left[2 \pi(1-2 k s) f_{1} t+\theta_{2}\right] \\
& +\frac{1}{2} \frac{D}{N-P} A_{1} \cos \left[2 \pi(1+2 k s) f_{1} t+\theta_{3}\right]+\omega(t)
\end{aligned}
$$

\section{Fault Injection Experiments and Results}

3.1. Hardware-in-the-Loop-Based Fault Injection Benchmark. A type of high-speed train traction drive system is mainly composed of a pantograph, traction and current transformers, an inverter, and a traction motor which uses the MT205 motor to form a traction drive system as shown in Figure 3 [17].

A fault injection module was built to simulate and inject the early weak fault of a broken rotor bar on the hardwarein-the-loop fault injection benchmark of a certain type of traction drive control system based on dSPACE [18-20]. The fault injection simulation platform can be download on the website http://gfist.csu.edu.cn/indexE.html. The schematic diagram of the traction drive control system with a fault injection module is shown in Figure 4. The hardware-inthe-loop fault injection benchmark is shown in Figure 5; it includes a real-time simulator, a fault injection unit (FIU), a physical traction drive control unit (TCU), and a realtime data acquisition and monitoring unit. The controller is a physical object. The dSPACE hardware includes a DS1007 CPU board, a DS5203 field-programmable gate array (FPGA) board, a DS4004 digital I/O board, and a DS2103 multichannel high-precision D/A board.

3.2. Fault Injection Module. The internal composition of the fault injection module is shown in Figure 6.

The stator current is represented by the fault injection module according to (22); the current is composed of four parts. The Ramp in the module is the value of A; Fcn realizes the calculation of damage factor D in (8); Fcn1 implements the calculation of $(1 / 2)(D /(N-P))$; Inl represents the input fundamental current. Subsystem is used to measure the fundamental current amplitude $A_{1}$. Multiply the output of Fcn1 by the subsystem output to obtain the fault characteristic current amplitude. The output of Subsystem 1 is the fault characteristic current of frequency $1-2 k s$. The output of 


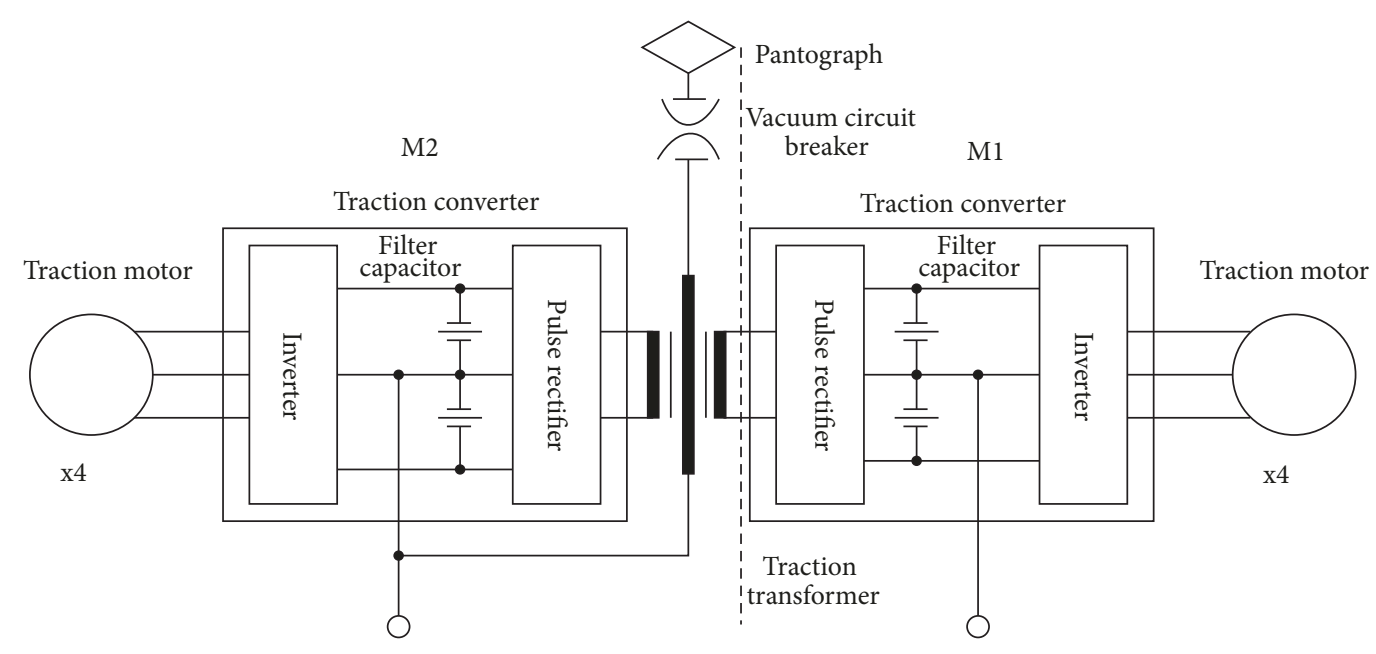

FIGURE 3: Schematic diagram of a traction drive system for a certain type of high-speed train.

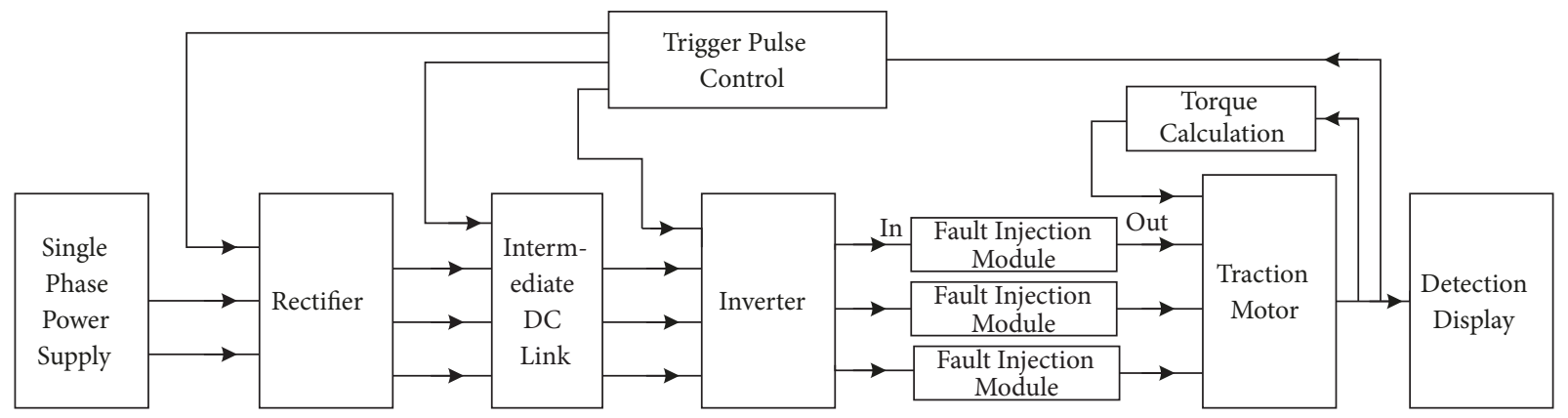

FIGURE 4: A schematic diagram of traction drive control system with fault injection module.

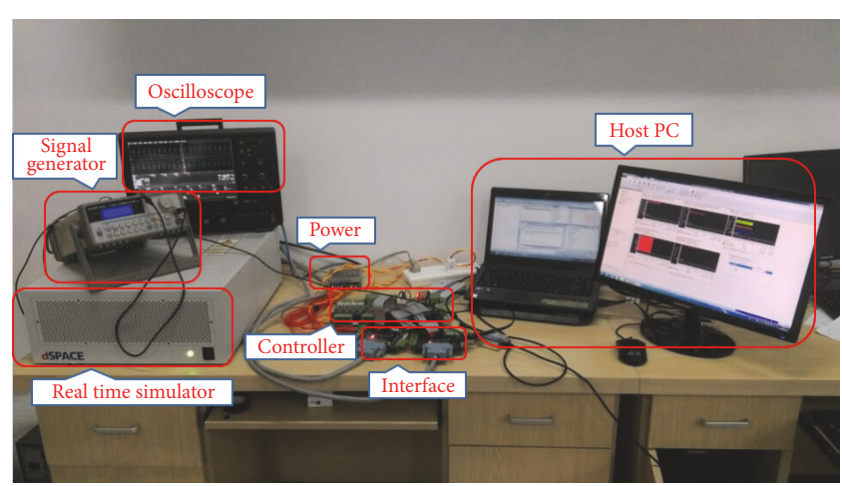

FIGURE 5: Hardware-in-the-loop fault injection benchmark for a certain type of traction drive control system.

Subsystem 2 is the fault characteristic current of frequency $1+2 k s$. Band-Limited White Noise is $\omega(t)$ in (22).

In the same way, when the traction motor encounters other types of faults, such as stator winding interturn shortcircuit fault, air gap eccentrici, and bearing fault $[21,22]$, the stator current will also generate the corresponding frequency current with fault characteristics. Therefore, by changing the second and third parts of (22) and modifying the fault injection module of Figure 5, the fault injection of other fault types or multiple faults (multiple faults occur simultaneously) can be realized.

3.3. Experimental Results and Analysis. Using the above hardware-in-the-loop fault injection benchmark and fault injection module and the concept of accelerated testing, the time taken for the rotor bar from normal to completely broken in the fault injection module can be set by itself. This simulates the more lengthy process that the actual broken rotor bar actually goes through, thus achieving traction, which realizes the early weak fault injection simulation of the broken rotor bar for the traction motor.

The physical concept of this method is clear, simple, and feasible. The time is set to a step length of 1e- 6 , the simulation time is $6 \mathrm{~s}$, and an oscilloscope was used to read and display each reference data. When the broken rotor bar fault occurs, the curves of the train running speed, traction motor angular speed, and torque are shown in Figure 7. It can be seen from Figure 7 that the torque and speed of the traction motor fluctuate slightly, causing the train speed to fluctuate which increases with the severity of the broken rotor bar fault.

Figure 8 shows the current of stator A-phase winding. According to Figures 7 and 8 , it is not possible to determine the traction motor had broken rotor bar fault. The FFT 


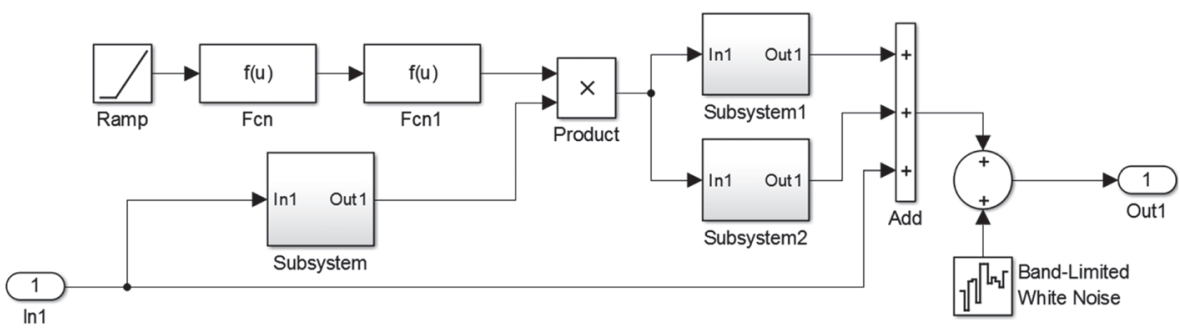

FIGURE 6: Fault injection module.

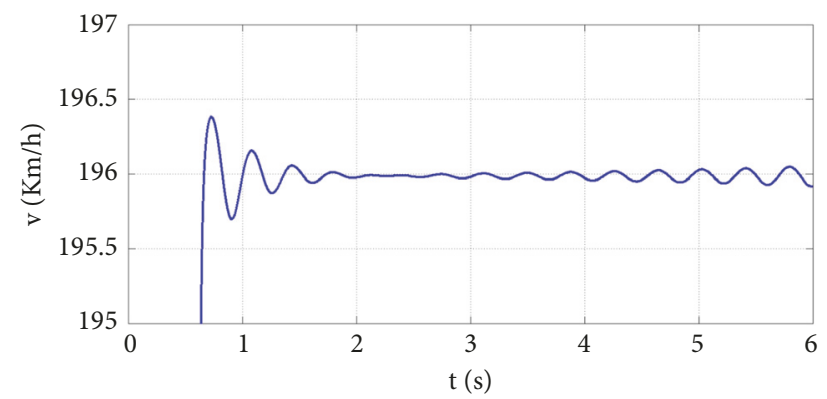

(a) Train speed

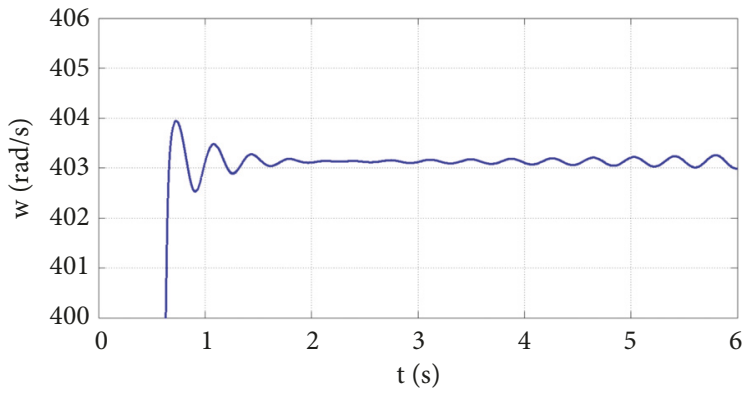

(b) Angular speed of traction motor

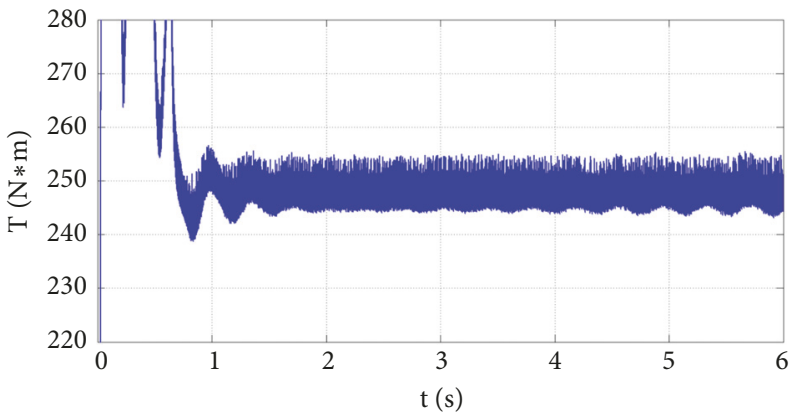

(c) Electromagnetic torque traction motor

FIGURE 7: Train speed and mechanical characteristics of traction motor.

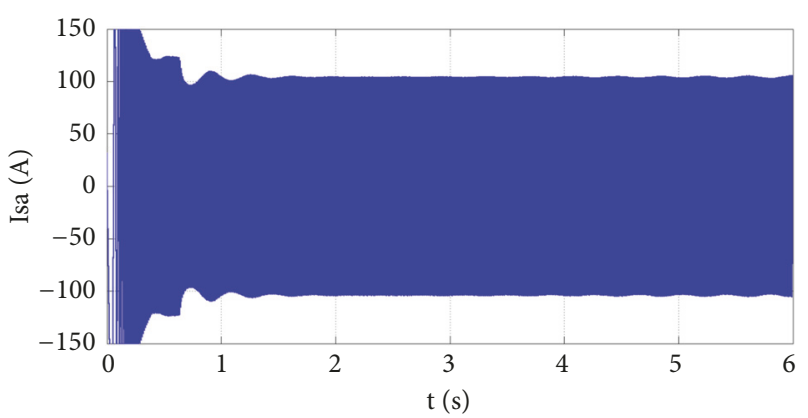

FIGURE 8: Current of stator A-phase winding.

spectrum analysis of the stator current can be used to extract the fault characteristic $(1 \pm 2 s) f_{1}$.

The traction motor was tested with damage factors $\mathrm{D}$ of $1,0.8,0.5,0.3,0.2$, and 0 (Normal) to verify the effectiveness of the fault injection method at different fault severities. Also, the stability of the stator current FFT spectrum was analyzed to extract the fault characteristic frequency of the broken rotor bar fault. At this point, the theoretical values of the fundamental wave frequency and slip are $131.1 \mathrm{~Hz}$ and 0.019 , respectively.

Spectral analysis of the stator current data of the motor under steady state operation of the simulation platform was performed. The ordinate of the spectrogram adopts logarithmic indexing, which can highlight fault characteristic components and show minor faults more clearly. Therefore, all data were normalized based on the amplitude of the fundamental frequency component. Figure 9 shows the stator current FFT spectrum analysis under different damage factors.

From Figure 9, the fundamental frequency during steady state operation was $131.1 \mathrm{~Hz}$. The frequencies at $126.1 \mathrm{~Hz}$ and $135.8 \mathrm{~Hz}$ located on the left and right sides of the fundamental frequency are the characteristics frequencies that reflect the broken rotor bar fault, which are $(1 \pm 2 s)$ times of the original frequency $f_{1}$. The larger the damage factor, the more 
TABLE 1: The current frequency and amplitude of fault characteristics under different damage factors.

Fundamental Fault characteristic The amplitude of fault characteristic current under different damage factors (Normalization FFT) Frequency $(\mathrm{Hz})$ frequency $(\mathrm{Hz})$ $(\mathrm{dB})$

\begin{tabular}{ccccccccc}
\hline$f_{1}$ & $f_{b 1}$ & $f_{b 2}$ & $D=1$ & $D=0.8$ & $D=0.5$ & $D=0.3$ & $D=0.2$ & $D=0$ \\
\hline 131.1 & 126.1 & 135.8 & -69.94 & -70.26 & -70.98 & -72.14 & -72.62 & none \\
\hline
\end{tabular}

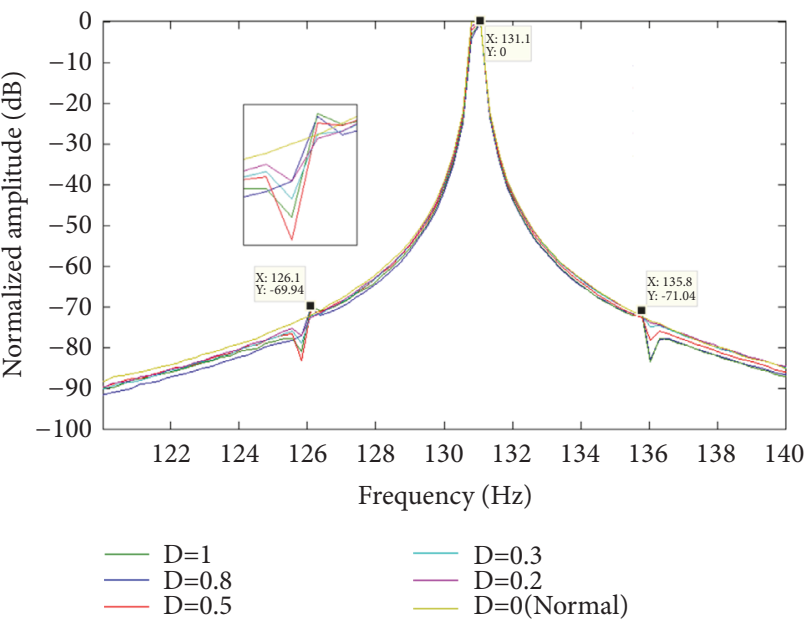

FIGURE 9: Stator current spectra under different fault severity.

obvious the fault characteristics. The current frequency of fault characteristics and amplitude under different damage factors are shown in Table 1. The experimental results are in accordance with the theoretical analysis results which verified the accuracy of the current characteristics analysis and fault injection.

\section{Conclusion}

The destructiveness and randomness of the traction motor broken rotor bar fault limit its simulation. In this paper, starting from the variation law of the resistance of the rotor bar metal in the fatigue evolution process, the corresponding relationship between the fracture severity of a single rotor bar and phase resistance of the traction motor was obtained. The relationship between characteristic fault current component and the single rotor bar fault severity of the traction motor was established and the stator current expressions were constructed when the rotor bar has fault. The simulation injection of the fracture gradient process was implemented on the hardware-in-the-loop fault injection benchmark and the experimental results were verified.

The experimental results show that the early weak fault current characteristics of the traction motor broken rotor bar fault were analyzed and the fault injection module was constructed accordingly. The effective early weak fault injection of the broken rotor bar was realized on a certain type of high-speed train hardware-in-the-loop fault injection benchmark. In addition, the fault injection method can modify the output signal of the injection module and simulate other single or multiple fault modes of the traction motor.
The fault injection module can flexibly implement fault setup and injection, information collection and analysis, which provides an effective means for the study of the traction motor fault.

\section{Data Availability}

The data used to support the findings of this study are available from the corresponding author upon request.

\section{Conflicts of Interest}

The authors declare that there are no conflicts of interest regarding the publication of this paper.

\section{Acknowledgments}

This work was supported in part by the National Natural Science Foundation of China (61490702, 61773407, 61725306, and 61751312), in part by the Foundation for Innovative Research Groups of the National Natural Science Foundation of China (61621062), in part by the Science and Technology Project in Hunan Province Hunan Science and Technology Agency of China (2016TP1023), and in part by the Research Project in Hunan Province Education Department of China (16C1450 and 17C1441).

\section{References}

[1] R. G. Martin, J. A. Antonino-Daviu, and G.-A. Capolino, "Advances in electrical machine, power electronic, and drive condition monitoring and fault detection: state of the art," IEEE Transactions on Industrial Electronics, vol. 62, no. 3, pp. 17461759, 2016.

[2] S. A. Taher, "A Novel Technique for Rotor Bar Failure Detection in Single-Cage Induction Motor Using FEM and MATLAB/SIMULINK," Mathematical Problems in Engineering, vol. 2011, Article ID 620689, 14 pages, 2011.

[3] J. T. Yin, Y. F. Xie, and C. H. Yang, "Monitoring of incipient rotor bars broken fault in traction motors based on RVMD method," Control and Decision, vol. 33, no. 3, pp. 497-502, 2018.

[4] M. A. Moussa, M. Boucherma, and A. Khezzar, "A detection method for induction motor bar fault using sidelobes leakage phenomenon of the sliding discrete fourier transform," IEEE Transactions on Power Electronics, vol. 32, no. 7, pp. 5560-5572, 2017.

[5] G. Georgoulas, V. Climente-Alarcon, J. A. Antonino-Daviu et al., "The use of a multilabel classification framework for the detection of broken bars and mixed eccentricity faults based on the start-up transient," IEEE Transactions on Industrial Informatics, vol. 13, no. 2, pp. 625-634, 2017. 
[6] T. A. Garcia-Calva, D. Morinigo-Sotelo, and R. De Jesus Romero-Troncoso, "Non-uniform time resampling for diagnosing broken rotor bars in inverter-fed induction motors," IEEE Transactions on Industrial Electronics, vol. 64, no. 3, pp. 23062315, 2017.

[7] S. B. Lee, D. Hyun, T.-J. Kang et al., "Identification of false rotor fault indications produced by online MCSA for mediumvoltage induction machines," IEEE Transactions on Industry Applications, vol. 52, no. 1, pp. 729-739, 2016.

[8] S. Choi, E. Pazouki, J. Baek, and H. R. Bahrami, "Iterative condition monitoring and fault diagnosis scheme of electric motor for harsh industrial application," IEEE Transactions on Industrial Electronics, vol. 62, no. 3, pp. 1760-1769, 2015.

[9] H. Zhu, J. Hu, L. Gao, and H. Huang, "Fault diagnosis of incipient broken rotor bars for squirrel-cage induction motor under continuous variable load condition," Chinese Journal of Scientific Instrument, vol. 35, no. 7, pp. 1646-1653, 2014.

[10] V. Thomas, K. Vasudevan, and V. Kumar, "Online cage rotor fault detection using air-gap torque spectra," IEEE Transactions on Energy Conversion, vol. 18, no. 2, pp. 265-270, 2003.

[11] F. Filippetti, M. Martelli, G. Franceschini, and C. Tassoni, "Development of expert system knowledge base to on-line diagnosis of rotor electrical faults of induction motors," in Proceedings of the 1992 IEEE Industry Applications Society Annual Meeting, IAS 1992, pp. 92-99, USA, October 1992.

[12] J. Penman and A. Stavrou, "Broken rotor bars: their effect on the transient performance of induction machines," IEE Proceedings - Electric Power Applications, vol. 143, no. 6, pp. 449-457, 1996.

[13] J. S. Jiang, W. G. Zhang, Y. M. Guo, and D. Y. Ye, "The quantitative research of fatigue damage for metal materials," Materials Science and Engineering, vol. 18, no. 1, pp. 43-46, 2000.

[14] A. Balamurali, C. Lai, A. Mollaeian, V. Loukanov, and N. C. Kar, "Analytical investigation into magnet eddy current losses in interior permanent magnet motor using modified winding function theory accounting for pulsewidth modulation harmonics," IEEE Transactions on Magnetics, vol. 52, no. 7, pp. $1-5,2016$.

[15] S. Williamson and A. C. Smith, "Steady-state analysis of 3-phase cage motors with rotor-bar and end-ring faults," IEE Proceedings Part C Electric Power Applications, vol. 129, no. 3, pp. 93-100, 1982.

[16] F. Filippetti, G. Franceschini, C. Tassoni, and P. Vas, "AI techniques in induction machines diagnosis including the speed ripple effect," IEEE Transactions on Industry Applications, vol. 34, no. 1, pp. 98-108, 1998.

[17] J. T. Yin, Y. F. Xie, T. Peng et al., "Traction motor broken bar fault injection base on parameters of equivalent circuit," in Proceedings of the 2015 34th Chinese Control Conference (CCC), pp. 6325-6330, July 2015.

[18] C. Yang, C. Yang, T. Peng, X. Yang, and W. Gui, "A faultinjection strategy for traction drive control systems," IEEE Transactions on Industrial Electronics, vol. 64, no. 7, pp. 57195727, 2017.

[19] X. Yang, C. Yang, T. Peng, Z. Chen, B. Liu, and W. Gui, "Hardware-in-the-loop fault injection for traction control system," IEEE Journal of Emerging and Selected Topics in Power Electronics, vol. 6, no. 2, pp. 696-706, 2018.

[20] Z. Chen, S. X. Ding, T. Peng, C. Yang, and W. Gui, "Fault detection for non-gaussian processes using generalized canonical correlation analysis and randomized algorithms," IEEE Transactions on Industrial Electronics, vol. 65, no. 2, pp. 15591567, 2018.
[21] X. Song, J. Hu, H. Zhu, and J. Zhang, "Effects of the slot harmonics on the stator current in an induction motor with bearing fault," Mathematical Problems in Engineering, vol. 2017, Article ID 2640796, 11 pages, 2017.

[22] F. M. Garcia-Guevara, F. J. Villalobos-Piña, R. Alvarez-Salas, E. Cabal-Yepez, and M. A. Gonzalez-Garcia, "Stator fault detection in induction motors by autoregressive modeling," Mathematical Problems in Engineering, vol. 2016, Article ID 3409756, 7 pages, 2016. 


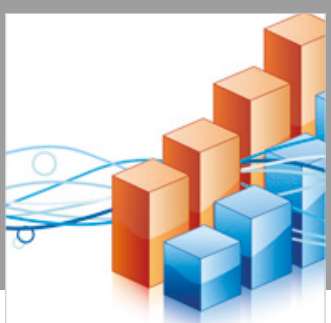

Advances in

Operations Research

\section{-n-m}
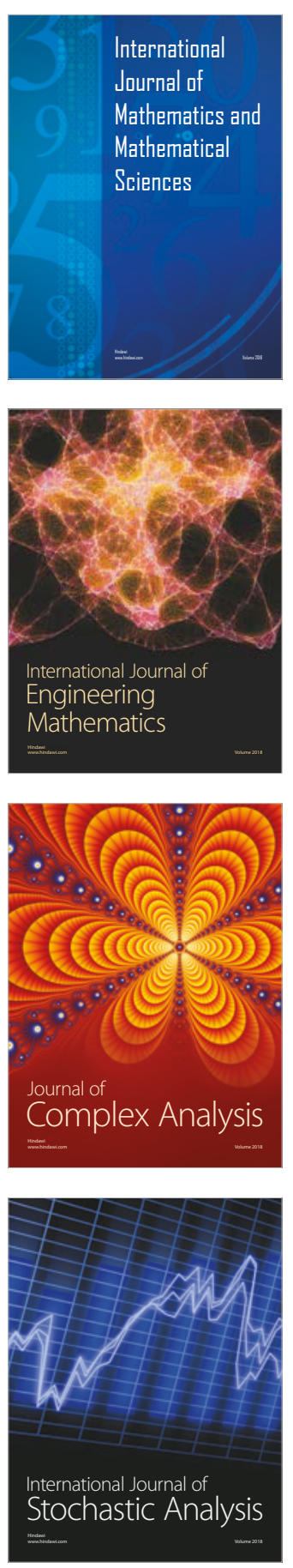
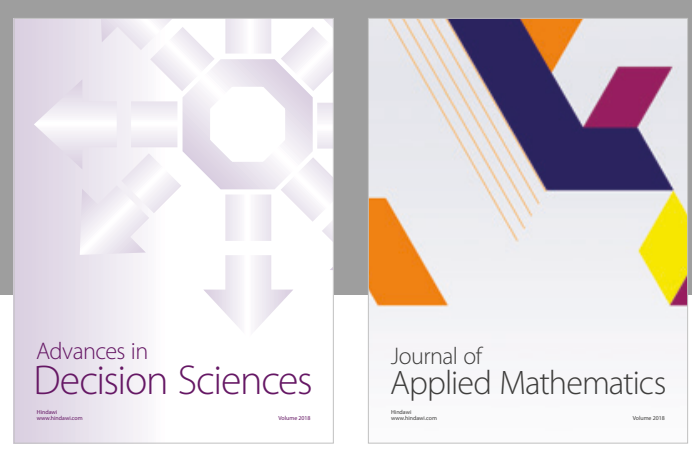

Journal of

Applied Mathematics
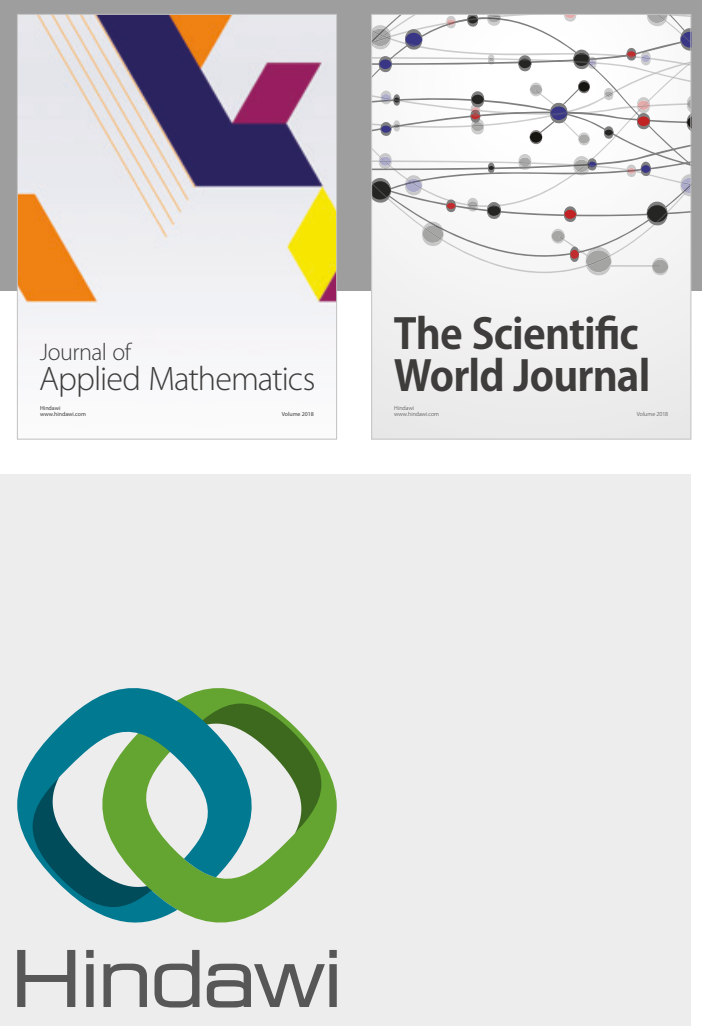

Submit your manuscripts at

www.hindawi.com

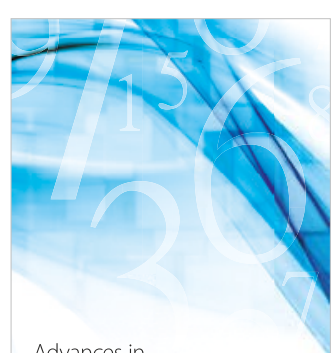

Advances in
Numerical Analysis
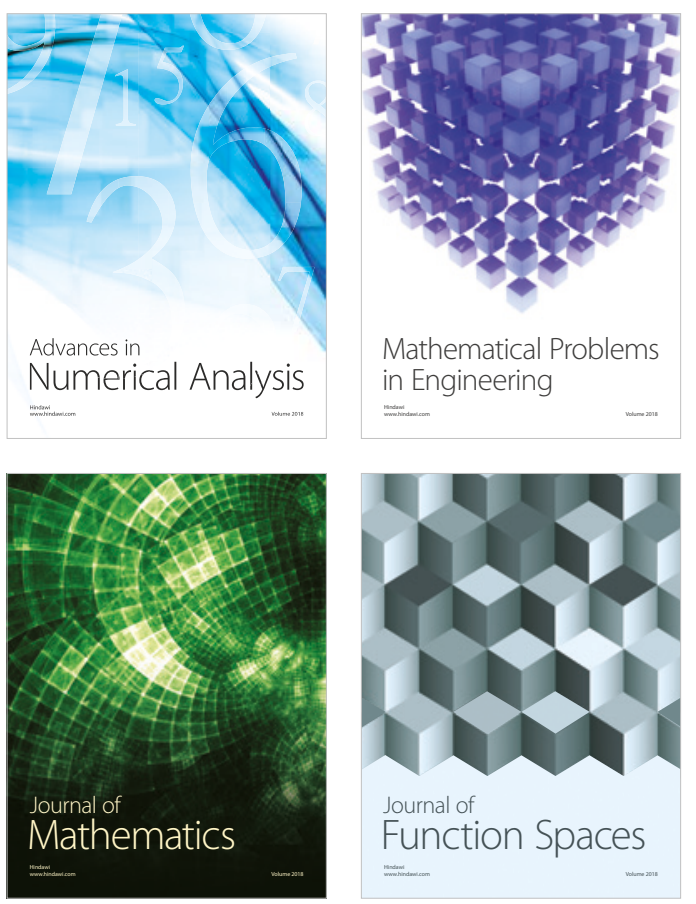

Mathematical Problems in Engineering

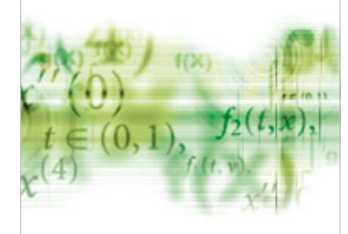

International Journal of

Differential Equations

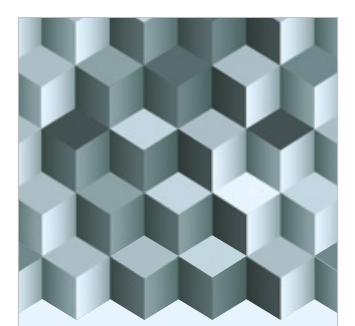

Journal of

Function Spaces

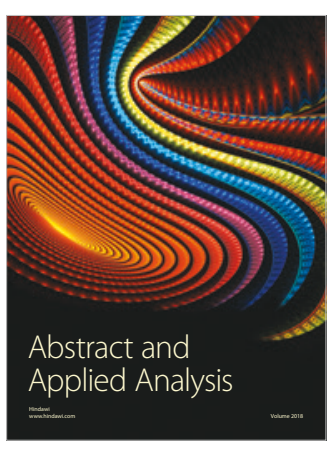

The Scientific

World Journal

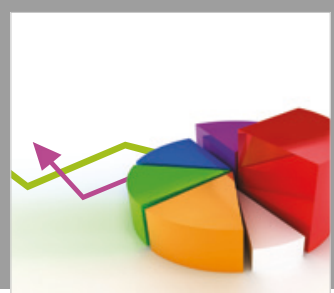

Journal of

Probability and Statistics
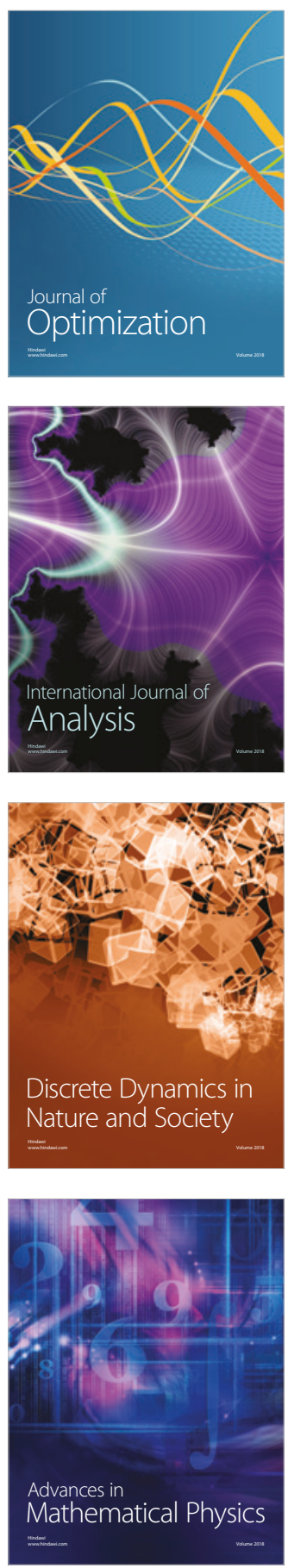